\title{
Lactobacillus Pentosus Ita23 and L. Acidipiscis \\ Ita44 Enhance Feed Conversion Efficiency and Beneficial Gut Microbiota in Broiler Chickens
}

ISSN 1516-635X Apr - Jun 2015 / v.17 / n.2 / 159-164

http://dx.doi.org/10.1590/1516-635x1702159-164

\section{-Author(s)}

\section{Altaher YW'}

Jahromi MFI

Ebrahim $\mathrm{R}^{\mathrm{I}}$

Zulkifli I'

Liang J'

Institute of Tropical Agriculture, Universiti Putra Malaysia, Serdang, 43400 Selangor Malaysia

\section{Mail Address}

Corresponding author e-mail address

Dr. Juan Boo Liang

Address: Institute of Tropical Agriculture, Universiti Putra Malaysia, Serdang, 43400

Selangor, Malaysia

Tel: +603 - 89471390

Fax: +603 - 89381612

Email: jbliang@upm.edu.my

\section{- Keywords}

Broiler chickens, cholesterol, Lactobacillus, low density lipoprotein, probiotics.

\section{ABSTRACT}

Although the use of probiotics especially Lactobacillus and Bifidobacteria species on growth and feed utilization in poultry production has been extensively studied, the results were inconsistent presumably because the mode of action of probiotic is multi-factorial and each probiotic strain may affect the host in a specific manner. This study investigated the probiotic effect of two strains of Lactobacillus (Lactobacillus pentosus ITA23 and Lactobacillus acidophilus ITA44; $10^{9}$ cells/kg feed) isolated from mulberry (Morus Alba) silage on the growth performance, cecal microbial population, and blood cholesterol of broiler chickens. One hundred twenty male broiler chicks (Cobb500) were randomLy allocated to two groups (control and treatment) of six replicates (cages) with 10 chicks per cage. Chicks in the control group received a standard diet and those in the treatment group received the same diet supplemented with $10^{9}$ cells of the above Lactobacillus per $\mathrm{kg}$ feed. Supplementation of Lactobacillus did not affect body weight gain (averaged $1604 \mathrm{~g}$ at 35 days old) but feed conversion ratio improved $(p<0.01)$ by $6.4 \%$ due to reduction in feed intake $(p<0.01)$ by birds in the treatment group. Supplementation also increased the population of Lactobacillus spp. and reduced pathogens $E$. coli in the cecal samples. Although Lactobacillus supplementation tends to reduce serum total cholesterol, low-density lipoprotein (LDL) and triglyceride concentrations, these values were not significantly different from those of the control group. Results of this study showed that $L$. pentosus ITA23 and $L$. acidophilus ITA44 are potential probiotics to be used in poultry diets.

\section{INTRODUCTION}

The biggest challenge of present-day commercial poultry production is the availability of quality feed at sustainable and stable price (Lyayi, 2008). Most of of the feed ingredients used for commercial poultry production in many newly developed and developing countries in Asia are imported from different sources depending on their availability and price, and often at the sacrifice of quality. Thus, many approaches, including the use of growth promoter additives (including antibiotics), are used to promote growth and feed conversion efficiency to ensure profitability (Pelicano et al., 2002). In view of the severe restriction or total ban on the use of antibiotics as growth promoters in livestock and poultry production, probiotics have been suggested as an alternative to antibiotics (Ahmad, 2006). A probiotic is a live microbial feed supplement that is beneficial to the host animal by inhibiting pathogens to allow the growth of beneficial gut microflora (Jin et al, 1998; Ghadban, 2002). The proposed mechanisms of pathogen inhibition by the probiotic microorganisms include competition for nutrients, production of 
antimicrobial conditions (e.g. low pH) and compounds (bacteriocins), competition for binding sites on the intestinal epithelium, and stimulation of the immune system (Rolfe, 2000). The diversity of possible modes of action thus suggests that the efficacy of probiotics is strain specific and has to be demonstrated for each strain (Shinde, 2012).

Lactobacillus spp is one of the most extensively studied genera of beneficial bacteria used as probiotics. Another important role of probiotic bacteria is their ability to metabolically influence serum cholesterol and triglyceride levels (Lin et al.1989; Taranto et al. 1998). The above property of probiotic has been more intensely studied in relation to human. However, there is evidence suggesting that Lactobacillus feed supplementation can reduce cholesterol and fatty acid composition of broiler chickens (Kalavathy et al., 2006). The purpose of this study was to investigate the probiotic efficacy of two strains of Lactobacillus, namely L. pentosus ITA23 and L. acidipiscis ITA44 which were recently isolated from Mulberry (Morus Alba) silage in our laboratory.

\section{MATERIALS AND METHODS}

\section{Probiotic}

The probiotic efficacy of $L$. pentosus ITA23 and $L$. acidipiscis ITA44, isolated from mulberry (Morus Alba) silage, was examined in this study. These isolates have been shown to possess high acid and bile tolerance, antioxidant activity, and ability to produce fatty acids (unpublished data). The probiotics were prepared by culturing each inoculum in sterilized MRS broth (Merck, Germany) at $37^{\circ} \mathrm{C}$ for $24 \mathrm{~h}$. After incubation, the culture was centrifuged at $6000 \mathrm{rpm}$ for 6 minutes after which the pellet was washed with distilled water by centrifugation at $8000 \mathrm{rpm}$ for 12 minutes. The pellets containing the probiotic cells was freeze dried, grinded, and stored at $-80^{\circ} \mathrm{C}$ until further use. For the feeding trial, the pellets from both Lactobacillus (each one containing $10^{9}$ cells/g) were mixed (1:1) before it was added to the feed.

\section{Experimental design}

Birds were cared in accordance to the Animal Care and Use Protocol of the Universiti Putra Malaysia Animal Care and Use Committee. One hundred twenty dayold male broiler chicks (Cobb500) from a commercial hatchery in Malaysia were used for the study. The chicks were randomLy allocated to two treatments with six replicates of 10 birds per cage (replicate). Birds in the control group received a standard diet while the second group (probiotic) received similar diet containing $0.1 \%$ of a mixture of $L$. pentosus ITA23 and $L$. acidophilus ITA44; $10^{9}$ cells $/ \mathrm{kg}$ feed. Birds were fed a starter diet for the first 21 days and a finisher diet from days 22 to 35 formulated to meet or exceed their nutrient requirements of NRC (1990) (Table 1). Clean drinking water was offered ad libitum during the experimental period. Birds were inspected daily to ensure their welfare, and mortality was recorded when it occurred. They were weighed weekly on cage basis throughout the experimental period to determine average body weight (BW) and body weight gain (BWG). Feed intake (FI) per cage was recorded weekly, and weekly feed conversion ratio (FCR) was calculated as Fl/BWG.

Table 1 - Ingredient composition and nutrient content of the basal diet

\begin{tabular}{lcc}
\hline $\begin{array}{l}\text { Ingredient (g/kg unless otherwise } \\
\text { stated) }\end{array}$ & $\begin{array}{c}\text { Starter } \\
\text { (1 to } 21 \text { days) }\end{array}$ & $\begin{array}{c}\text { Finisher } \\
\text { (22 to 35days) }\end{array}$ \\
\hline Ground yellow corn & 538.9 & 603.0 \\
\hline Soybean meal & 361.9 & 305.6 \\
\hline Fish meal & 30.0 & 30.0 \\
\hline Palm oil & 37.4 & 37.4 \\
\hline $60 \%$ choline chloride & 2.5 & 2.0 \\
\hline Trimix & 1.0 & 1.0 \\
\hline Salt (Na Cl) & 2.0 & 1.0 \\
\hline DL-methionine & 1.8 & 0.4 \\
\hline Limestone & 13.0 & 13.0 \\
\hline Dicalcium phosphate & 11.5 & 6.5 \\
\hline Total & 1000.0 & 1000.0 \\
\hline
\end{tabular}

\begin{tabular}{lcc}
\hline Calculated composition & & \\
\hline Crude protein & 217.0 & 198.1 \\
\hline Crude fat & 63.6 & 65.6 \\
\hline Crude fibre & 38.0 & 27.8 \\
\hline Calcium & 11 & 9.8 \\
\hline Phosphorus & 4.5 & 3.5 \\
\hline Metabolisable energy $(\mathrm{kcal} / \mathrm{kg})$ & 3000 & 3080
\end{tabular}

'Trimix (per kg Trimix): iron $100 \mathrm{~g}$; manganese $110 \mathrm{~g}$; copper $20 \mathrm{~g}$; zinc $100 \mathrm{~g}$; iodine $2 \mathrm{~g}$; selenite $0.2 \mathrm{~g}$; cobalt $0.6 \mathrm{~g}$; santoquin $0.6 \mathrm{~g}$; folic acid $0.33 \mathrm{~g}$; thiamin 0.83 g; pyridoxine $1.33 \mathrm{~g}$; biotin $2 \% 0.03 \mathrm{~g}$; riboflavin $2 \mathrm{~g}$; cyanocobalamin $0.03 \mathrm{~g}$; D-calcium pantothenate $3.75 \mathrm{~g}$; niacin $23.3 \mathrm{~g}$; retinol $2000 \mathrm{mg}$; cholecalciferol 25 mg; $\alpha$-tocopherol 23,000 mg IU.

On day 35 , birds were sacrificed individually by cervical dislocation and blood samples were collected for the determination of serum cholesterol level. The cecal content of two birds per replicate was collected 
and stored in liquid nitrogen pending microbial DNA extraction and determination of bacterial population using Quantitative Real-Time PCR.

\section{DNA extraction}

DNA was extracted from cecal samples and pure cultures by using the QIAamp DNA Stool Mini Kit (Qiagen Inc., Valencia, CA) according to the manufacturer's protocols. The extracted DNA was stored at $-20^{\circ} \mathrm{C}$ until use. The extracted DNA from pure cultures was used for the production of high concentration of target DNA using normal PCR and preparation of a standard curve. $P C R$ products were purified using the MEGA quick$\operatorname{spin}^{\mathrm{TM}}$ (Intron Biotechnology, Inc.), and the purity and concentration of DNA in each sample were measured using a Nanodrop ND-1000 spectrophotometer and number of copies of a template DNA per $\mathrm{mL}$ of elution buffer was calculated using the standard formula. Standard curves were constructed using serial dilutions of the PCR products from pure cultures of each bacterial group.

\section{Quantitative Real Time PCR}

The following specific primers (16S rRNA region) were used to quantify different bacteria populations according to the method of Navidshad et al. (2012):

For total microbes: F-5'-CGG CAA CGA GCG CAA CCC-3' and R-5'-CCA TTG TAG CAC GTG TGT AGC C-3' (Denman \& McSweeney, 2006); for Lactobacillus: F-5'-CAT CCA GTG CAA ACC TAA GAG-3' and R- 5'GAT CCG CTT GCC TTC GCA-3' (Wang et al., 1996), for Escherichia coli F-5'-GTG TGA TAT CTA CCC GCT TCG C-3' and R-5'-AGA ACG CTT TGT GGT TAA TCA GGA-3' (Frahm \& Obst, 2003), For Enterococcus genus F-5'- CCC TTA TTG TTA GTT GCC ATC ATT-3' and R-5'-ACT CGT TGT ACT TCC CAT TGT-3' (Rinttila et al., 2004) and for Enterobacter: F- 5'-CAT TGA CGT TAC CCG CAG AAG AAG C-3' and R-5'-CTC TAC GAG ACT CAA GCT TGC-3' (Bartosch et al., 2004). Real-time PCR was performed with BioRad CFX96 Touch (BioRad, USA) using optical grade plates. The $P C R$ reaction was performed on a total volume of $25 \mu \mathrm{L}$ using the iQTMSYBR Green Supermix (BioRad, BioRad, USA). Each reaction included $12.5 \mu \mathrm{L}$ SYBR Green Supermix, $1 \mu \mathrm{L}$ of each Primer, $1 \mu \mathrm{L}$ of DNA samples and $9.5 \mu \mathrm{L} \mathrm{H}_{2} \mathrm{O}$. The reaction conditions for DNA amplification were $94^{\circ} \mathrm{C}$ for 5 min, 40 cycles of $94^{\circ} \mathrm{C}$ for $20 \mathrm{~s}, 55^{\circ} \mathrm{C}, 58^{\circ} \mathrm{C}$, or $60^{\circ} \mathrm{C}$ for $30 \mathrm{~s}$ for total microbes, Lactobacillus and other bacteria respectively, and $72^{\circ} \mathrm{C}$ for $20 \mathrm{~s}$. To confirm the specificity of amplification, melting curve analysis was carried out after the last cycle of each amplification. The expected size of the amplified fragments were 145bp for total microbes, 341 bp for Lactobacillus group, 82 bp for Escherichia coli, 144 bp for Enterococcus genus, and 195 for Enterobacter, and were verified on a 2\% (wt/ vol) Agarose gel for $40 \mathrm{~min}$ at $80 \mathrm{~V}$.

To calculate the amount of DNA in digesta samples, first, the calibration standards constructed by amplification of known amounts of target DNA were used to convert the Ct values into amounts of DNA. The estimated values were expressed as $\log ^{10}$ of each bacteria cell number per gram of digesta.

\section{Statistical analysis}

Statistical analyses of the data were performed by comparing birds fed probiotic with the control for each parameter using a two-tailed $t$-test with unequal group variance using SAS Statistical Software (2008). The significance level was set at $p<0.05$.

\section{RESULTS AND DISCUSSION}

Feed is the main component of the total production costs in the poultry industry and therefore, improving the efficiency of feed utilization is essential for profitability. Results of this study show that supplementation of the two Lactobacillus spp did not affect BWG, but significantly $(p<0.01)$ improved FCR compared with the control feed. The FCR improvement is attributed the lower $\mathrm{Fl}$ of birds in the Lactobacillus supplementation group (Table 2). This result is in agreement with some earlier studies (Kabir et al., 2004; Timmerman et al., 2006), whose authors suggested that FCR improved in Lactobacillus supplemented birds because probiotic supplementation enhances the activity and release of digestive enzymes thus resulting in better digestion and absorption of nutrients.

Table 2 - Effect of probiotics (Lactobacillus pentosus ITA23 and $L$. acidipiscis ITA44) on the feed intake, body weight, weight gain, and feed conversion ratio in broiler chickens between 1 to 35 days of age.

\begin{tabular}{|c|c|c|c|}
\hline \multirow[t]{2}{*}{ Parameter } & \multicolumn{2}{|c|}{ Treatment } & \multirow[t]{2}{*}{ Significant } \\
\hline & Control & Probiotic & \\
\hline Feed intake (g) & $3004.3^{a} \pm 85.2$ & $2829.3^{b} \pm 33.9$ & $* *$ \\
\hline Body weight (g) & $1640.0 \pm 25.9$ & $1656.6 \pm 29.1$ & NS \\
\hline Weight gain (g) & $1600.4 \pm 25.5$ & $1607.1 \pm 28.6$ & NS \\
\hline Feed conversion ratio & $1.88^{a} \pm 0.06$ & $1.76^{b} \pm 0.02$ & $\star *$ \\
\hline
\end{tabular}

Data are means \pm standard deviation; NS: not significant $(p>0.05) ;{ }^{* *}$ : significant at $p<0.01$ 
In his review, Shinde (2012) reported that the current knowledge on the mode of action of probiotics is only superficial. Several modes of action have been proposed to explain for the beneficial effects of probiotics (Figure 1); however, these effects appear to be multi-factorial and each probiotic strain may affect the host in a specific manner. The positive effects of the Lactobacillus strains on FCR in this study could have resulted from a direct nutritional effect of the probiotic alone or in combination with a health effect, with the probiotic acting as a bio-regulator of the intestinal microbiota and reinforcing the host's natural defense systems (Shareef et al., 2009). Other authors, such as Anderson et al (1999) and Saulnier et al., (2009), mentioned that the beneficial effects of the suppression of pathogenic gut microbiota by probiotics include reduced nutrient utilization by the pathogenic microorganisms and thus more nutrients are made available for the host, as well decreased levels of toxic microbial metabolites that interfere with the host's growth.

Lactobacilli comprise of a large and diverse group of gram positive, non-spore forming, catalase negativerod bacteria, which are capable of producing lactic acid as the main end-product of carbohydrate fermentation
(Pelinescu et al., 2009). By producing acids (such as acetic and lactic acids) and other compounds that inhibit the growth of toxin-producing pathogenic bacteria, lactobacilli and other useful bacteria are considered as probiotics (Suskovic et al. 2010; Shokryazdan et al. 2014). As mentioned above, one of the main features of lactobacilli is their ability to produce lactic acid that reduces the $\mathrm{pH}$ of intestinal tract. Low $\mathrm{pH}$ environments favor the growth of gram positive bacteria (such as Bifidobacteria and Lactobacillus) but not of gram negative pathogenic microbes, such as E-coli and Salmonella, because of the sensitivity of their cell membrane in the acidic condition (Suskovic et al., 2010). In addition, by suppressing the production of toxic compounds that may change the morphology of the intestinal wall and reduce the colonization of pathogens on the intestinal wall, probiotics prevent damage to the epithelial cells (Saulnier et al., 2009, Shokryazdan et al. 2014) allowing better absorption. The dietary supplementation of Lactobacillus in this study did not affect total gut microbial population, but significantly $(p<0.01)$ increased the population of lactobacilli and reduced that of E-Coli in the cecum samples of broilers (Figure 2). This positive effect on the

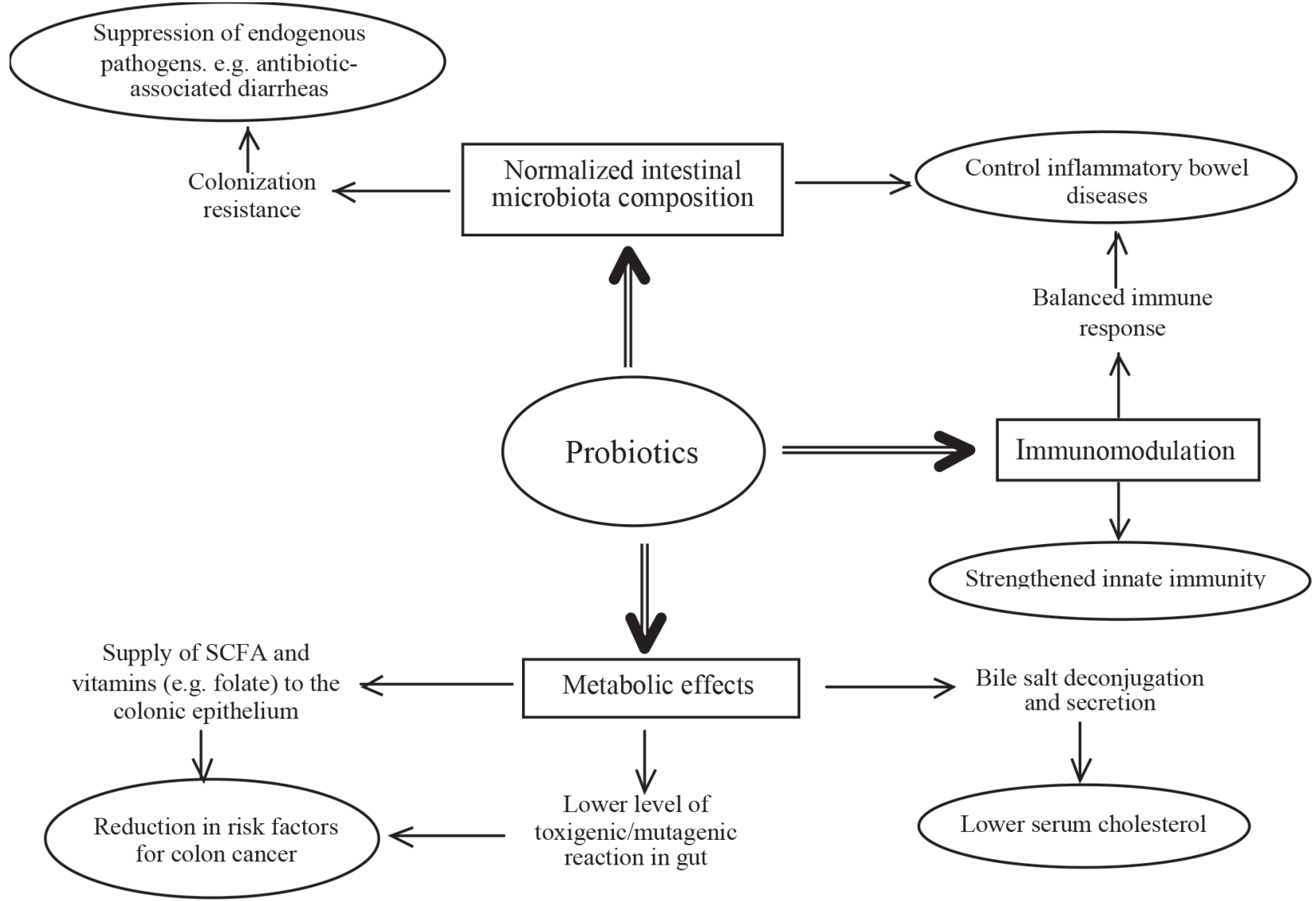

Figure 1 - Mode of action of probiotics (modified from Shinde, 2012) 


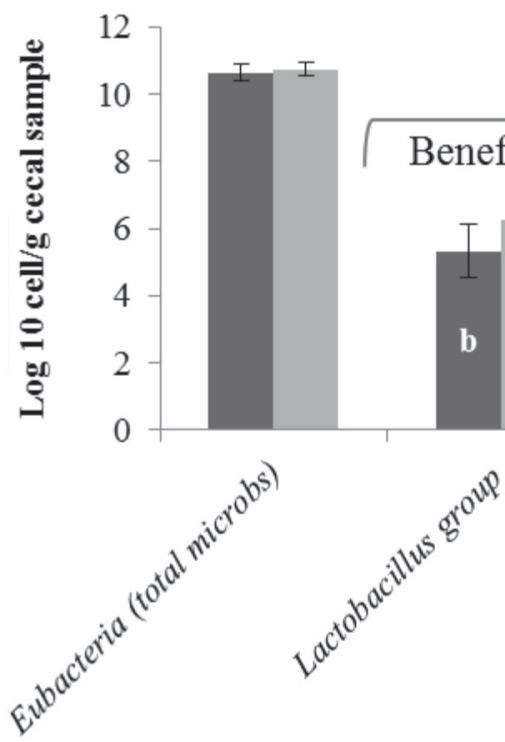

- Control $=$ Probiotic
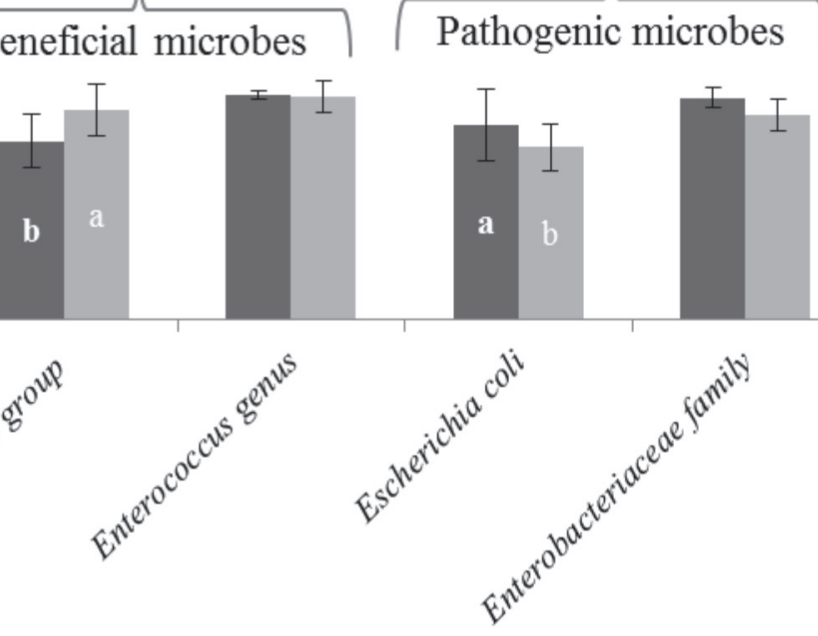

Figure 2 - Effect of probiotics (Lactobacillus pentosus ITA23 and L. acidipiscis ITA44) on the cecal bacteria of 35-day-old broiler chickens

gut microbiota may have resulted in a more efficient nutrient digestion and absorption in the Lactobacillus treatment group, thereby improving their FCR.

Cholesterol is essential for many body functions because it acts as a precursor of certain hormones and vitamins and it is an important component of cell membranes and nerve cells. It is known that elevated levels of blood cholesterol or other blood lipids are considered risk factors for developing of human coronary heart diseases (Lim et al. 2004). Although it may vary from person to person, the lipid component of diet affects serum cholesterol and triglyceride levels. Consumers are increasingly concerned with the consumption of animal products (eggs, meat and milk) because of their high lipid contents. Therefore, a challenge of present-day commercial poultry producers is to produce good quality products (e.g. meat and eggs with lower fat content) at a competitive cost.

Another known mode of action of probiotics is their metabolic effect on the reduction of cholesterol levels through deconjugation of bile salts in the host animal (Figure 1). Some studies reported that probiotics may potentially reduce serum triglyceride levels of 35-day-old broiler chickens. cholesterol levels (Kim et al., 2008; Belviso et al., 2009). Kalavathy et al. (2006) reported that although the supplementation of Lactobacillus cultures (consisting of four species) lowered liver cholesterol levels of broiler chickens, this effect was not observed in the muscle. The same authors also observed that the Lactobacillus cultures reduced the fat content of the liver, muscle, and carcass of broiler chickens, but showed very little potential to modify fatty acid composition. Our results show that supplementation of the two strains of Lactobacillus lowered serum total cholesterol levels, but low density lipoprotein (LDL) and triglyceride levels were not different $(p>0.05)$ from the control birds (Figure 3 ). Since the modes of action of probiotics appear to be multi-factorial and strain specific, the efficacy of probiotics to reduce and modify the fatty acid composition of animal products (meat and eggs) requires further investigations.

Results of this study indicate that supplementation of a mixture of $L$. pentosus ITA23 and L. acidipiscis ITA44 improved the FCR of broiler chickens. However, the effect on serum cholesterol and other blood

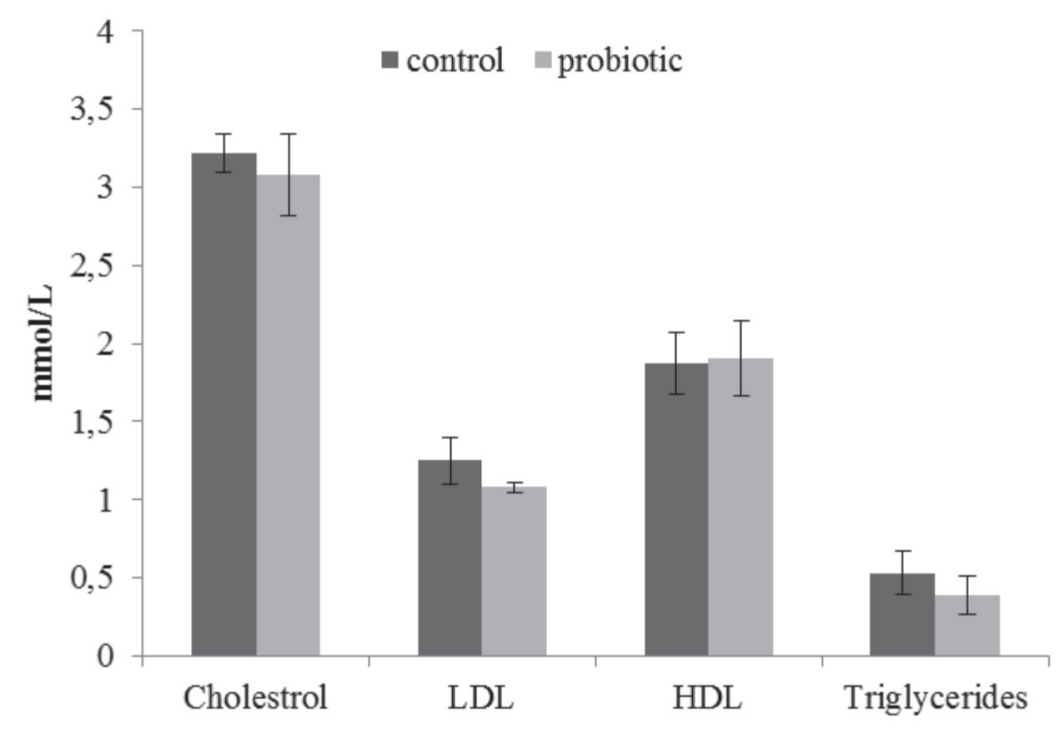

Figure 3 - Effect of probiotics (Lactobacillus pentosus ITA23 and L. acidipiscis ITA44) on serum cholesterol and 
parameters was less evident. Although the actual mechanism by which the supplementation improved FRC was unclear, it is likely that Lactobacillus spp act as a probiotic by suppressing pathogenic bacteria, thereby providing a better environment for nutrient digestion and absorption.

\section{ACKNOWLEDGEMENT}

This study was supported by the LRGS Fasa 1/2012 (Universiti Putra Malaysia) provided by the Ministry of Education Malaysia.

\section{REFERENCES}

Ahmad I. Effect of probiotics on broilers performance. International Journal of Poultry Science 2006;5(6):593-597.

Anderson DB, McCracken VJ, Aminov RJ, Simpson JM, Mackie RJ, Vestegem MWA, Gaskins HR. Gut microbiology and growth promoting antibiotics in swine. Pig News and Information 1999;20:115-122.

Bartosch S, Fite A, Macfarlane GT, McMurdo ME. Characterization of bacterial communities in feces from healthy elderly volunteers and hospitalized elderly patients by using real-time PCR and effects of antibiotic treatment on the fecal microbiota. Applied and Environmental Microbiology 2004;70:3575-3581.

Belviso S, Giordano M, Dolci P, Zeppa G. In vitro cholesterol-lowering activity of Lactobacillus plantarum and Lactobacillus paracasei strains isolated from the Italian Castelmagno PDO cheese. Dairy Science and Technology 2009;89:169-176

Denman SE, McSweeney CS. Development of a real-time PCR assay for monitoring anaerobic fungal and cellulolytic bacterial populations within the rumen. FEMS Microbiolology Ecology 2006;58:572-582

Frahm E, Obst U. Application of the fluorogenic probe technique (TaqMan $\mathrm{PCR}$ ) to the detection of Enterococcus spp. and Escherichia coli in water samples. Journal of Microbiological Methods 2003;52:123-131.

Ghadban GS. Probiotics in broiler production. Archiv Für Geflügelkunde 2002;66: 49-58.

Jin LZ, Ho YW, Abdullah N, Jalaludin S. Growth performance, intestinal microbial populations and serum cholesterol of broilers fed diets containing Lactobacillus cultures. Poultry Science 1998;77:1259-1265.

Kabir SML, Rahman MM, Rahman MB, Ahmed SU. The dynamics of probiotics on growth performance and immune response in broilers. International Journal of Poultry Science 2004;3:361-364.

Kalavathy R, Abdullah N, Jalaludin S, Wong M, Ho YW. Effects of Lactobacillus feed supplementation on cholesterol, fat content and fatty acid composition of the liver, muscle and carcass of broiler chickens. Animal Research 2006;55(1):77-82.

Kim Y, Whang JY, Whang KY, Oh S, Kim SH. Characterization of the cholesterol-reducing activity in a cell-free supernatant of Lactobacillus acidophilus ATCC 43121. Bioscience, Biotechnology, and Biochemistry 2008; $72: 1483-1490$

Lim HJ, Kim S, Lee W. Isolation of cholesterol-lowering lactic acid bacteria from human intestine for probiotic use. Journal of Veterinary Science 2004:5:391-395.
Lin SY, Ayres JW, Winkler W, Sandine WE. Lactobacillus effects on cholesterol: in vitro and in vivo results. Journal Dairy Research 1989;72:2885-2889.

Lyayi EA. Prospects and challenges of unconventional poultry feedstuffs. Poultry Science 2008;5(4):186-194.

Navidshad B, Liang JB, Jahromi MF. Correlation coefficients between different methods of expressing bacterial quantification using real time PCR. International Journal of Molecular Sciences 2012;13(2):21192132.

NRC - National Research Council. Nutrient requirements of poultry. $9^{\text {th }}$ rev. Washington, DC: National Academy Press; 1990

Pelicano ERL, Souza PA, Souza HBA. Prebióticos e probióticosnanutrição de aves. Ciências Agrárias e da Saúde 2002;2(1):59-64

Pelinescu DR, Sasarman E, Chifiriuc MC, Stoica I, Nohita AM, Avram I, et al. Isolation and identification of some Lactobacillus and Enterococcus strains by apolyphasic taxonomical approach. Biotechnology Letters 2009; 14:4225-4233.

Rinttila T, Kassinen A, Malinen E, Krogius L, Palva A. Development of an extensive set of $16 \mathrm{~S}$ rDNA-targeted primers for quantification of pathogenic and indigenous bacteria in faecal samples by real-time PCR Journal Applied Microbiology 2004;97:1166-1177

Rolfe RD. The role of probiotic cultures in the control of gastrointestinal health. Journal of Nutrition 2000;130:396-402.

SAS Institute. SAS Online Doc 9.2. Cary, NC; 2008

Saulnier D, Spinler JK, Gibson GR, Versalovic J. Mechanisms of probiosis and prebiosis: considerations for enhanced functional foods. Current Opinion in Biotechnology 2009;20:135-141.

Shareef AM, Al-Dabbagh ASA. Effect of probiotic (Saccharomyces cerevisiae) on performance of broiler chicks. Iraqi Journal of Veterinary Science 2009:23:23-29.

Shinde PB. Probiotic: an overview for selection and evaluation. International Journal of Pharmacy and Pharmaceutical Science 2012:4(2):14-21.

Shokryazdan P, Sieo CC, Kalavathy R, Liang JB, Noorjahan BA, Jahromi MF, Ho YW. Probiotic Potential of Lactobacillus Strains with Antimicrobial Activity against Some Human Pathogenic Strains. BioMed Research International 2014:927268.

Suskovic J, Blazenka K, Beganovic J, Pavunc AL, Habjanic K, Matosic S Antimicrobial activity - the most important property of probiotic and starter lactic acid bacteria. Food Technology and Biotechnology 2010:48:296-307

Taranto MP, Medici M, Perdigon G, Ruiz Holgado AP, Valdez GF Evidence for hypocholesterolemic effect of Lactobacillus reuteri in hypercholesterolemic mice. Journal of Dairy Science 1998:81:23362340

Timmerman HM, Veldman A, Van den Elsen E, Rombouts FM, Beynen AC. Mortality and growth performance of broilers given drinking water supplemented with chicken-specific probiotics. Poultry Science 2006;85:1383-1388.

Wang RF, Cao WW, Cerniglia CE. PCR detection and quantitation of predominant anaerobic bacteria in human and animal fecal samples. Applied and Environmental Microbiology 1996;62:1242-1247. 